\title{
Design of UV Laser Parameters on Grooving Depth for Die Attach Film
}

\author{
Te-Jen Su, Yi-Feng Chen, Jui-Chuan Cheng, and Chien-Liang Chiu \\ Department of Electronic Engineering, National Kaohsiung University of Science and Technology, \\ No. 415, Jiangong Rd., Sanmin Dist., Kaohsiung City 80778, Taiwan
}

(Received Ocrtober 30, 2017; accepted January 24, 2018)

Keywords: UV laser, grooving depth, die attach film

A die attach film (DAF) is a material that is used to attach dies to a substrate or lead frame during the die attach manufacturing step in the semiconductor IC assembly process, and the DAF UV laser half cut is a manufacturing step in the semiconductor IC assembly process, and the cutting performance affects the die bond chip pickup yield. Therefore, the optimization of laser half cut parameters is very important. In this work, different laser parameters were studied to find the significant factor parameters followed by the fine tuning of the optimization condition. Experimental results showed that the laser power and cutting feed speed are the significant parameters for achieving laser cutting quality. According to the design of experiment (DOE) results, in the laser power range of $0.5-0.8 \mathrm{~W}$, the cutting feed speed range is 45-65 $\mathrm{mm} / \mathrm{s}$ and the grooving depth is $15-20 \mu \mathrm{m}$, which are the optimized conditions of a 20 - $\mu \mathrm{m}$-thick DAF.

\section{Introduction}

For the past 20 years, increasing the die strength of an IC package has been a challenge. Some novel solution has been developed, such as dicing before grinding (DBG), which is a semiconductor assembly process, where the die is separated during the wafer backside grinding manufacturing step after the wafer half-cut dicing. This increases the chip strength by improving the wafer backside chipping performance over the previous dicing after grinding (DAG) process. ${ }^{(1,2)}$ DBG can improve the backside chipping from 50 to $5 \mu \mathrm{m} .{ }^{(3)}$ The main difference between DBG and DAG is in the manufacturing process sequence. In DAG, the wafer dicing process is after wafer backside grinding, while in DBG the process flow is reversed; the wafer dicing is before the wafer grinding and the DAG wafer dicing is full cut, whereas DBG wafer dicing is half cut, as shown in Fig. 1.

DBG includes three additional manufacturing steps, namely, (1) wafer half cut, (2) die attach film (DAF) laser half cut, and (3) wafer cooling expand. In DAG, the wafer and DAF are cut and separated at the same time, while in DBG, the wafer and DAF are cut at different manufacturing steps, with the wafer half cut by a mechanically sawing diamond dicing blade,

*Corresponding author: e-mail: sutj@kuas.edu.tw

http://dx.doi.org/10.18494/SAM.2018.1791 


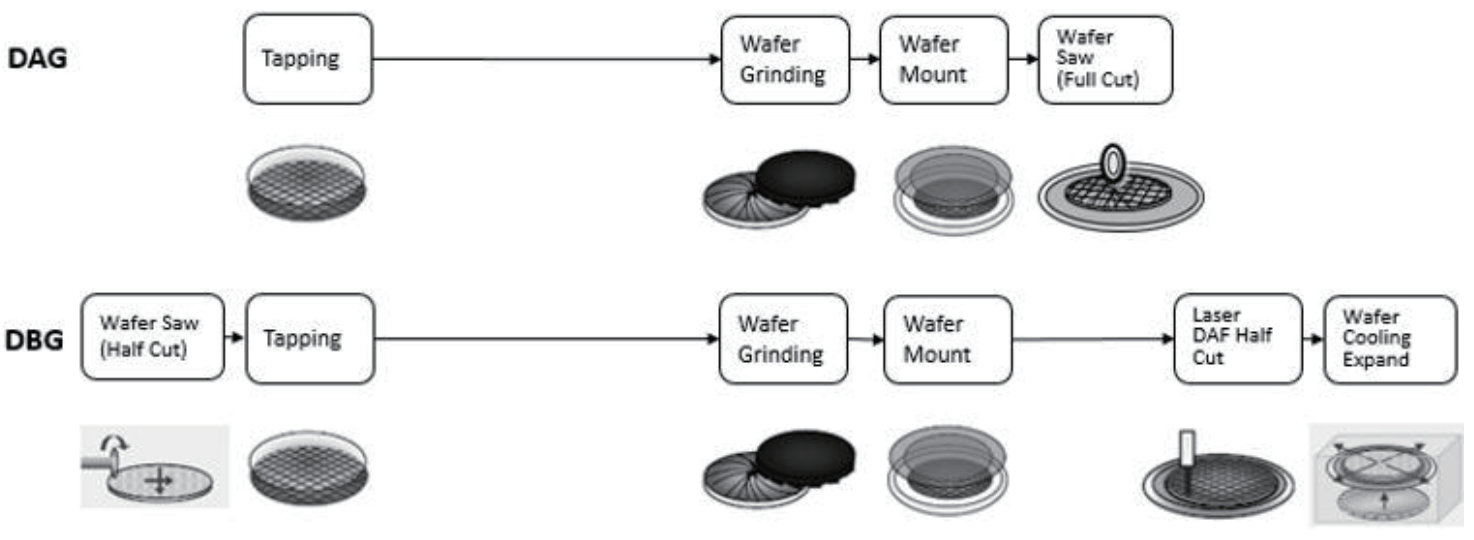

Fig. 1. Comparison of DAG and DBG process flow sequences.

and the DAF cut approaching the UV laser. The entire DBG process is shown in Fig. 2, where wafer half cut dicing is the first step, and DAF laser half cut manufacturing step is the 7th step.

The DAF laser half cutting and wafer cooling expansion manufacturing steps are shown in Fig. 3. The laser pulse is defocused on the DAF surface then a groove trench is formed, the DAF is mounted on the wafer backside after the wafer backside grinding and stress relief manufacture steps. The grooving depth of the laser does not exceed the film thickness, so the film is not completely penetrated. Rather, the DAF separation is completed in the following wafer cooling expansion manufacturing step, the cooling setting is $0-15{ }^{\circ} \mathrm{C}$, because the film material is an elastomer at room temperature, which difficult to separate; when the film is at $0{ }^{\circ} \mathrm{C}$, it is brittle and easy to separate. The distance of the wafer expansion is around $10 \mathrm{~mm}^{(4)}$

In this work we conducted experiments to identify the optimal parameters for laser half cut grooving, and thus optimized the cutting accuracy and final product quality. The target depth is $15-20 \mu \mathrm{m}$.

DAF has been popularly applied to IC package assembly. ${ }^{(5-8)}$ DAF is a film attached using an epoxy adhesive to the backside of the wafer after the wafer grinding and stress relief manufacture steps, to the object of attachment on the lead frame, or to the substrate of the assembly die bond manufacturing step: DAF includes the following material.

- Epoxy resin

- Phenol resin

- Filler

- Acrylic copolymer

\section{Methodology}

The experiment equipment uses a DFL-7160 (Disco Co.) model laser cut machine and an ultraviolet laser. The DAF has a thickness of $20 \mu \mathrm{m}$ and a length is 12 inches.

The main laser parameters include laser power, cutting feed speed, and pulse frequency. ${ }^{(9-11)}$ The initial experiment focuses on the laser power parameter with the experimental conditions summarized in Table 1. Ten conditions of 0.1 to $1.0 \mathrm{~W}$ were processed with speed fixed at 100 


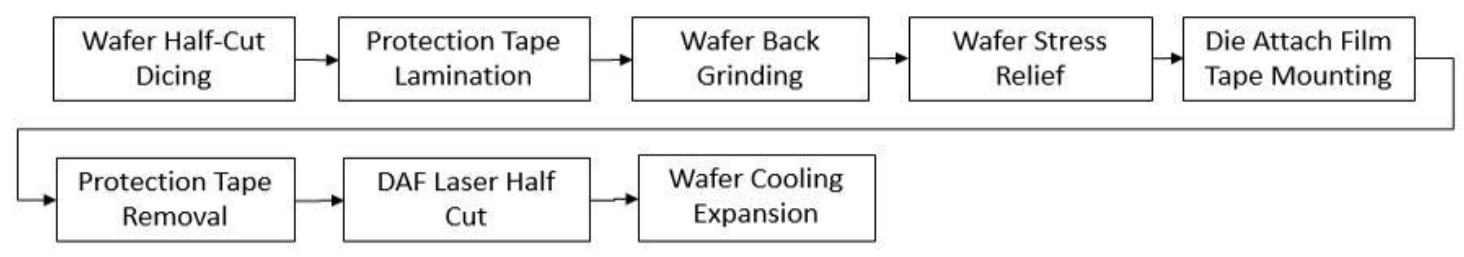

Fig. 2. DBG process flow.

$\underline{\text { DAG DAF separate }}$
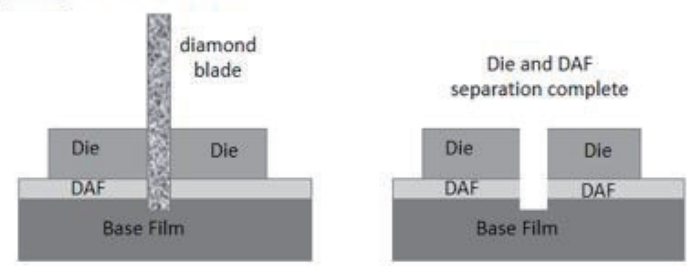

DBG DAF separate
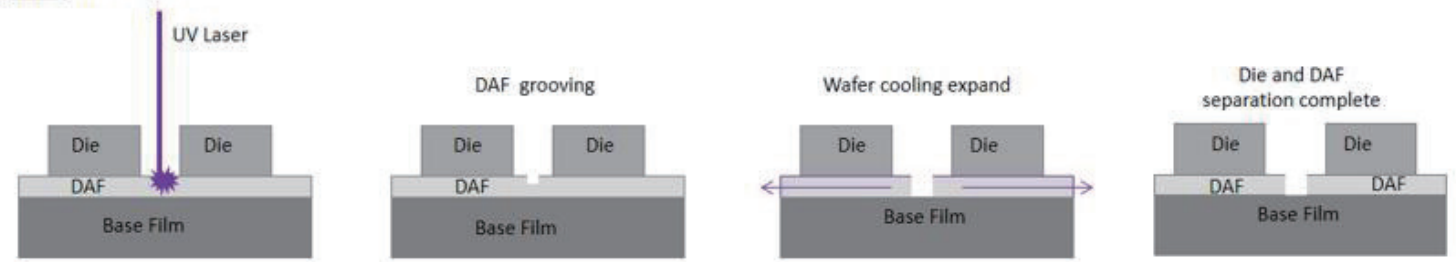

Fig. 3. (Color online) Comparison of DAF separation and manufacturing steps between DAG and DBG processes. In DAG, the process die and DAF are separated at the same time by a diamond blade. In DBG, the DAF is separated by the UV laser. In this manufacturing step, the dies have already been separated. The UV laser creates a groove that is half of the film thickness. The DAF is completely separated in the following wafer cooling expand step.

Table 1

Laser power experiment conditions.

\begin{tabular}{ccc}
\hline Experiment leg & Laser power $(\mathrm{W})$ & Cutting feed speed $(\mathrm{mm} / \mathrm{s})$ \\
\hline 1 & 0.1 & 100 \\
2 & 0.2 & 100 \\
3 & 0.3 & 100 \\
4 & 0.4 & 100 \\
5 & 0.5 & 100 \\
6 & 0.6 & 100 \\
7 & 0.7 & 100 \\
8 & 0.8 & 100 \\
9 & 0.9 & 100 \\
10 & 1.0 & 100 \\
\hline
\end{tabular}

$\mathrm{mm} / \mathrm{s}$ at high frequency. Laser grooving for all the ten conditions used the same DAF, after which the grooving kerf was observed using a $200 \times$ magnification microscope (Nikon). We took one measurement from each sample. 
Figure 4 shows the results of the laser grooving kerf on the DAF surface. The $0.1 \mathrm{~W}$ grooving kerf was noncontinuous, which will cause film separation failure, and thus this setting was not used in subsequent experiments. Exposures from 0.2 to $1.0 \mathrm{~W}$ produced continuous grooving kerf and effectively cut the DAF.

\section{Experimental Design}

In the following experiment, the laser power was set at $0.2,0.5,0.8$, and $1.1 \mathrm{~W}$ and the laser cutting feed speed was set at 20,30,40,50,60,70,80, 90, and $100 \mathrm{~mm} / \mathrm{s}$, (a total of 36 conditions for this experiment design), as shown in Table 2. This experiment focused on measuring the laser grooving depth, seeking a depth of 15-20 $\mu \mathrm{m}$ in a DAF of $20 \mu \mathrm{m}$ thickness.

The laser grooving depth is the response data of this design of experiment (DOE), which is the experimental result using a 3D laser scanning microscope (Keyence) to measure the laser grooving depth. We collected one sample from each condition. Figure 5 shows the laser grooving depth measurement method; the instrument scans the grooving kerf and measures the depth profile. The calculated depth is from the DAF surface to deepest poit of the grooving trench.

\section{Results}

\subsection{Analysis of variance (ANOVA)}

After the experiment and data collection, the laser grooving depth measurement data was subjected to ANOVA to analyze the significant factors. According to the two-factor variance
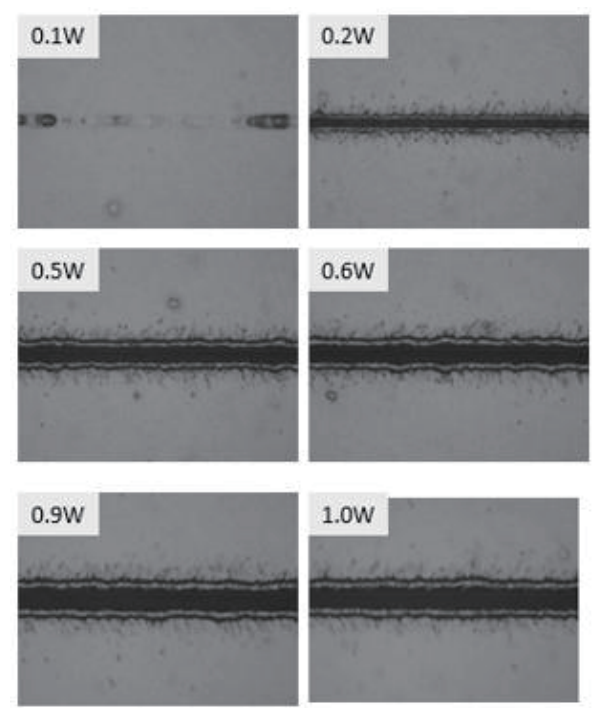
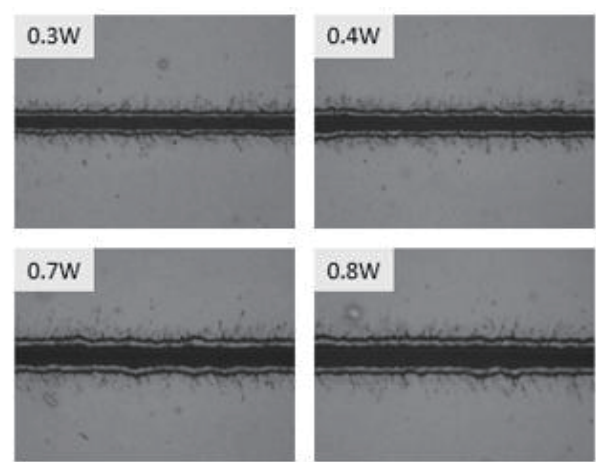

Fig. 4. Grooving on DAF achieved with laser powers of 0.1 to $1.0 \mathrm{~W}$. 
Table 2

DOE experiment condition table.

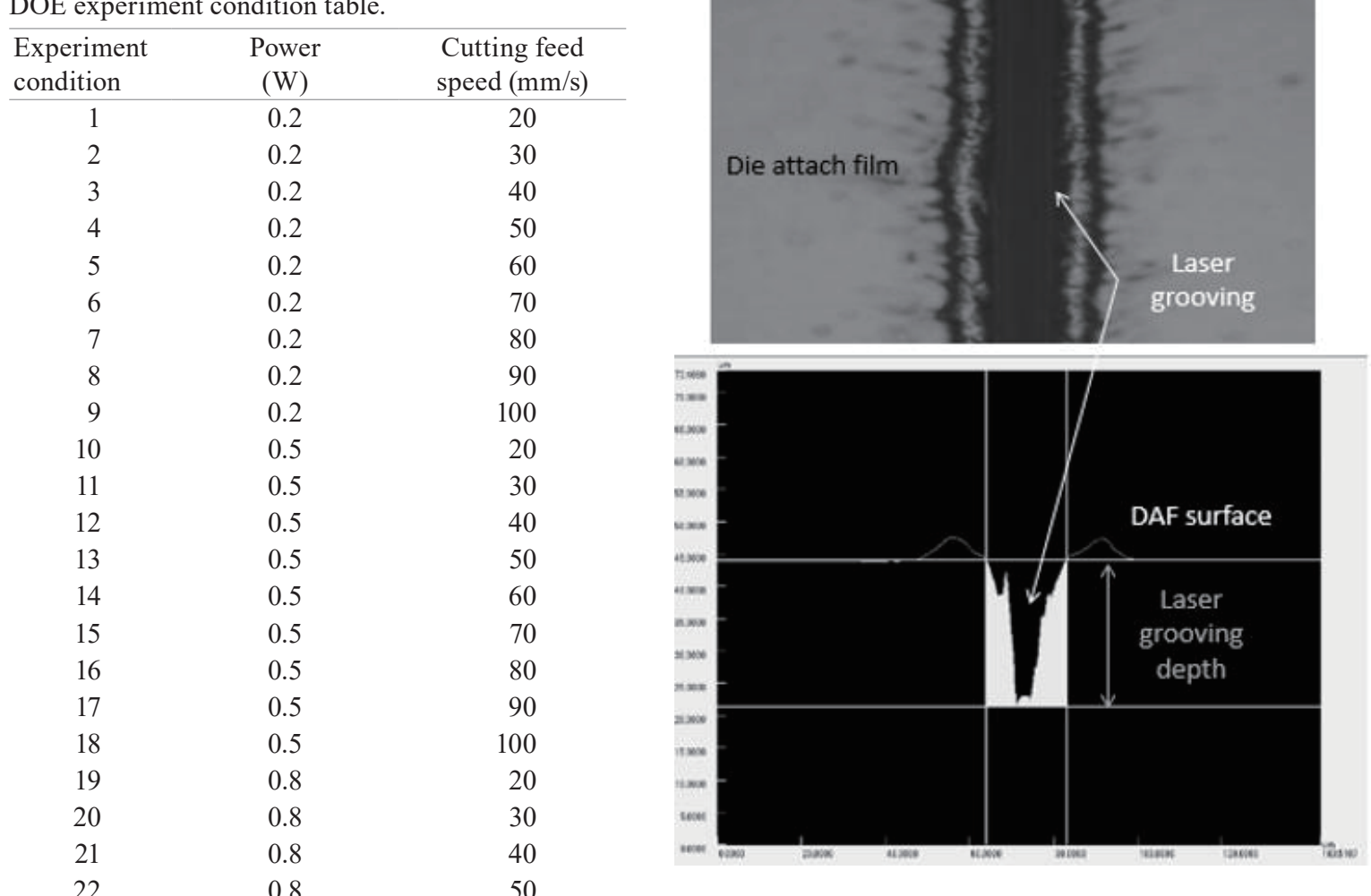

Fig. 5. Depth measurement method of laser grooving on DAF.

analysis, the experimental results show that, given a 99.9 confidence level, the $\mathrm{F}$ value for the laser cutting feed speed is 9.369 , which exceeds the critical value of 3.362, and the $P$ value of zero is far below 0.05 (Table 3). The F value for laser power is 124.989, which exceeds the critical value of 4.718 , and the $\mathrm{P}$ value of zero is far below 0.05 . Therefore, the analysis results indicate that the laser cutting feed speed and laser power are the main factors determining the grooving depth, which is in accordance with previous assumptions. 
Table 3

ANOVA results.

\begin{tabular}{lcccccc}
\hline Source & SS & DF & MS & F & P & Critical \\
\hline Speed $(\mathrm{mm} / \mathrm{s})$ & 293.6785 & 8 & 36.70981 & 9.369028 & 0.000 & 3.362867 \\
Power $(\mathrm{W})$ & 1469.208 & 3 & 489.736 & 124.9898 & 0.000 & 4.718051 \\
Error & 94.03702 & 24 & 3.918209 & - & - & - \\
Total & 1856.924 & 35 & - & - & - & - \\
\hline
\end{tabular}

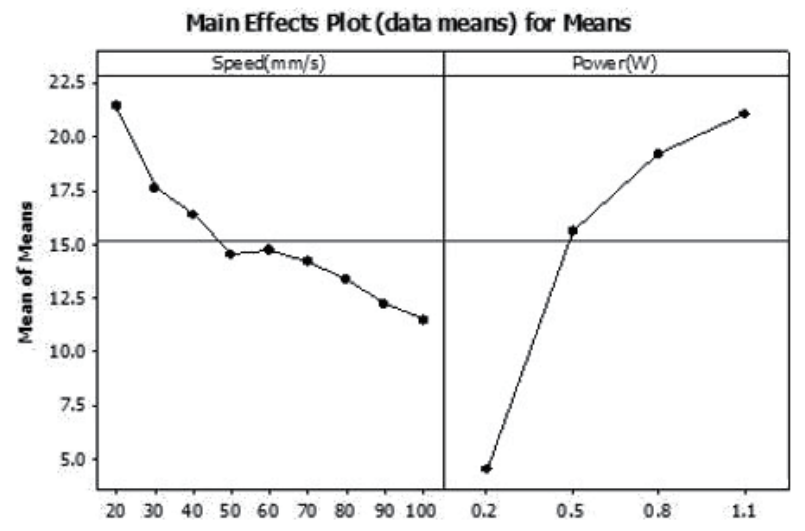

(a)

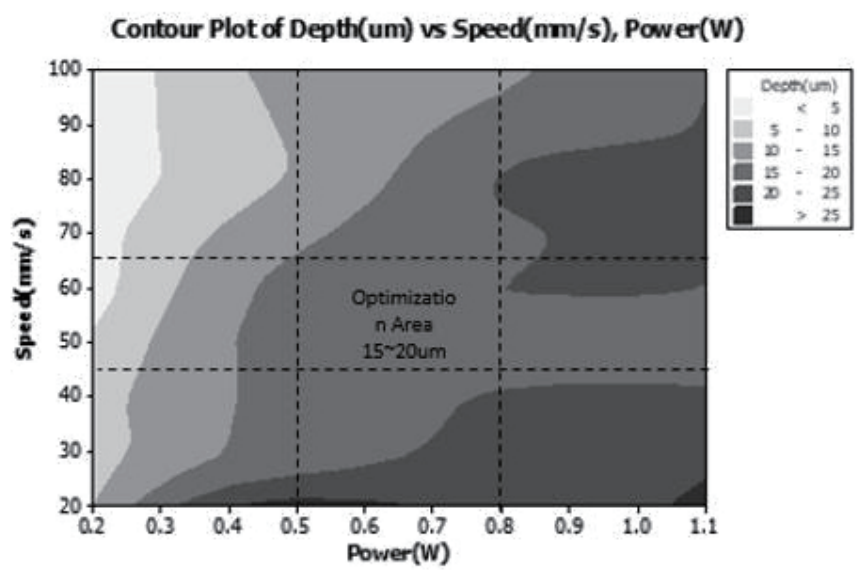

(b)

Fig. 6. (a) Main effect plot for means. (b) Contour plot of laser grooving depth.

\subsection{Contour plot analysis}

As shown in Fig. 6, according to the results of the main effect and contour plot analyses, the depth was less than $15 \mu \mathrm{m}$ when the laser power less than $0.5 \mathrm{~W}$. Laser power in the range of $0.5-0.8$ W with a laser cutting feed speed in the range of $45-65 \mathrm{~mm} / \mathrm{s}$ will produce a grooving depth of 15-20 $\mu \mathrm{m}$, as shown in Fig. 6, and are thus the optimal settings.

\section{Conclusions}

In this study, the experimental results provide the following conclusions for laser grooving half cut of a $20-\mu \mathrm{m}$-thick DAF: (1) laser power must exceed $0.1 \mathrm{~W}$ to completely separate the DAF at high frequency. (2) According to ANOVA, the laser power and cutting feed speed are the two key factors in the laser grooving depth of DAF laser grooving half cut. (3) To cut a $20-\mu \mathrm{m}$-thick DAF to a target depth of $15-20 \mu \mathrm{m}$, the optimal parameters are a laser power in the range of $0.5-0.8 \mathrm{~W}$ and a cutting feed speed of $45-65 \mathrm{~mm} / \mathrm{s}$.

In this study we have found the optimum parameters of the UV laser half cut, which have both theoretical and practical implications. However, design is not without flaws, namely, for optimum productivity and cost require a high unit per hour (UPH), yet the cutting feed speed affects the UPH and a speed of $65 \mathrm{~mm} / \mathrm{s}$ is not efficient for productivity. The next study will be on increasing the cutting speed and achieving excellent cutting quality. 


\section{Acknowledgments}

This work was supported partly by the Ministry of Science and Technology of Taiwan (R.O.C.) under Grant No. MOST 106-2221-E-151-003.

\section{References}

1 T. Imoto, M. Matsui, and C. Takubo: Proc. IEEE 51st Electronic Components and Technology Conf. (IEEE, Orlando, 2001) 552.

2 S. Takyu, T. Kurosawa, N. Shimizu, and S. Harada: Proc. IEEE 56th Electronic Components and Technology Conf. (IEEE, San Diego, 2006) 1623.

3 S. Takyu, J. Sagara, and T. Kurosawa: Proc. IEEE 58th Electronic Components and Technology Conf. (IEEE, Orlando, 2008) 1511.

4 Y. C. Lee and J. T. Lin: Proc. IEEE 10th Int. Microsystems, Packaging, Assembly and Circuits Technology Conf. (IEEE, Taipei, 2015) 348.

5 S. C. Kheng, M. Teo, and C. Lee: Proc. IEEE/CPMT 31st Int. Electronics Manufacturing Technology Symp. (IEEE, Petaling Java, 2006) 288.

6 S. N. Song, H. H. Tan, and P. L. Ong: Proc. IEEE 7th Electronics Packaging Technology Conf. (IEEE, Singapore, 2005) 848.

7 A. Jalar, M. F. Rosle, and M. A. A. Hamid: Proc. IEEE 9th Electronics Packaging Technology Conf. (IEEE, Singapore, 2007) 869.

8 T. S. Tsai, H. C. Chang, W. C. Li, C. P. Teng, and Y. S. Lai: Proc. IEEE/CPMT 32nd Int. Electronics Manufacturing Technology Symp. (IEEE, San Jose, 2007) 92.

9 H. C. Hsu, C. J. Han, L. M. Chu, S. J. W, C. C. Fu, S. L. Fu, B. Liu, C. Y. Chen, and P. C. Jung: Proc. IEEE 9th International Microsystems, Packaging, Assembly and Circuits Technology Conf. (IEEE, Taipei, 2010) 162.

10 M. S. Amri, D. Liew, and F. Harun: Proc. IEEE/CPMT 34th Int. Electronic Manufacturing Technology Symp. (IEEE, Melaka, 2010) 1.

11 K. W. Shi, L. T. Beng, and K. Y. Yow: Proc. IEEE 11th Electronics Packaging Technology Conf. (IEEE, Singapore, 2009) 846. 